\title{
Proceedings of the Annual Meeting of the Georgia Association of Mathematics Teacher Educators
}

\section{Basic Skills Testing in Math 2008}

Susie M. Lanier

Georgia Southern University, slanier@georgiasouthern.edu

Sharon Taylor

Georgia Southern University, taylors@georgiasouthern.edu

Donna B. Saye

Georgia Southern University, Dbsaye@georgiasouthern.edu

DOI

10.20429/gamte.2010.040105

Follow this and additional works at: https://digitalcommons.georgiasouthern.edu/gamte-proceedings

Part of the Mathematics Commons, and the Teacher Education and Professional Development Commons

\section{Recommended Citation}

Lanier, Susie M.; Taylor, Sharon; and Saye, Donna B. (2010) "Basic Skills Testing in Math 2008,"

Proceedings of the Annual Meeting of the Georgia Association of Mathematics Teacher Educators: Vol. 4 : Iss. 1 , Article 5.

DOI: $10.20429 /$ gamte.2010.040105

Available at: https://digitalcommons.georgiasouthern.edu/gamte-proceedings/vol4/iss1/5

This article is brought to you for free and open access by the Journals at Digital Commons@Georgia Southern. It has been accepted for inclusion in Proceedings of the Annual Meeting of the Georgia Association of Mathematics Teacher Educators by an authorized administrator of Digital Commons@Georgia Southern. For more information, please contact digitalcommons@georgiasouthern.edu. 
Basic Skills Testing in Math 2008

\author{
Susie M. Lanier Georgia \\ Southern University \\ slanier@georgiasouthern.edu \\ Sharon E. Taylor Georgia \\ Southern University \\ taylors@georgiasouthern.edu \\ Donna B. Saye Georgia \\ Southern University \\ dbsaye@georgiasouthern.edu
}

\begin{abstract}
Math 2008 is an Area F course for early childhood majors in the University System of Georgia. The course covers basic skills that pre-service teachers will most likely be teaching in their career. At Georgia Southern University, many students in the course do not possess or have forgotten these basic skills. In Fall 2009, a basic skills test was implemented for Math 2008. Students must earn a score of 90 or higher on the test in order to pass the course. The test not only serves to let students know their areas of weakness, but also informs the instructor's teaching. After the instructors implemented the skills test in this course, they found that most students started to take the material seriously, understand their weaknesses, and make an effort to learn. Also, the instructors are more aware of major gaps in the students' understanding of number sense and can focus instruction on those areas. The informal results of three instructors' experiences are described in this article.
\end{abstract}


Basic Skills Testing in Math 2008

Math 2008: Foundations of Numbers and Operations is a required course for all early childhood education majors in the University System of Georgia. At Georgia Southern University we require both early childhood and middle grades education majors to take the course. The focus of this course is number sense with topics concerning sets, logic, numeration systems, number theory, whole numbers, real numbers, fractions, decimals, ratio and percent. Obviously, these are important concepts for future elementary and middle school teachers. As instructors of these courses we use a variety of manipulatives and teaching methods. Building a better understanding of these mathematical concepts is stressed through modeling and group work. The books we have used for this course also stress developing these mathematical concepts. However, many of the books appear to view basic skills as a "given". After all, these students are in college and the material is elementary. Surely, they can do basic arithmetic!

While working with our students we realized that many of them cannot perform basic arithmetic skills, particularly without the aid of a calculator. Thus, we require the students complete most of the inclass assignments and tests without a calculator, and we supplement the course with various "skill" sheets. In addition, several instructors developed and began to administer a pre/post basic skills test to the students in Math 2008. These pre/post tests have been given for many years and were for the instructor's benefit. They were not connected to the student's grade in the course. Since the students did not feel pressure to perform well on the tests, they did not take them seriously. Due to our students' poor performance, we decided to make the "skills" test a legitimate part of the course. We developed a 25question basic skills test that is administered to all Math 2008 students each semester and serves as an exit requirement for the course. For students to successfully complete Math 2008, they must earn a minimum average of $\mathrm{C}$ and achieve at least $90 \%$ on the basic skills test. The test is intended to encourage students to improve their basic skills in arithmetic and to give instructors a measure of the students' abilities in this area. The test assesses the topics in the chart below.

\section{Topics Assessed on Basic Skills Test}

\author{
place value \\ rounding \\ addition of whole numbers \\ addition of decimals \\ subtraction of decimals \\ multiplication of whole numbers \\ multiplication of decimals \\ division of whole numbers \\ division of decimals
}

\author{
$\mathrm{LCM} / \mathrm{GCF}$ \\ equivalent fractions \\ mixed numbers and improper fractions \\ fraction/decimal conversion \\ addition of fractions \\ subtraction of fractions \\ multiplication of fractions \\ division of fractions \\ fraction/decimal/percent conversions
}

The questions on the skills test were chosen from among the 40 questions on the original pre/post test. These 40 questions were directly related to the mathematical content taught in the Math 2008 course, therefore providing content validation for the test. The top 25 questions selected by the instructors of the course formed the framework for the basic skills test. Multiple forms of the test were created by writing similar problems for each form.

The test is called a "basic skills test" because the students are asked to perform a skill. That is, students are required to use traditional algorithms to solve problems (e.g., multiplying fractions together). The focus is on the student's ability to "get a correct answer using an appropriate technique." This is quite different from the final exam given at the end of the course. The final exam is more conceptual. Students are required to demonstrate and explain mathematical concepts. On the final, students might draw area models to demonstrate multiplying fractions and would explain their method. 
Although the test may be administered at any point during the course, several instructors have decided to keep the pretest option by giving the test on the first day of class. Students achieving the minimum $90 \%$ or higher have met the requirement and never take the test again. Those students not meeting the minimum must repeat the test until they obtain an adequate score. Thus, six different forms of the test were created.

The basic skills test has been a requirement since Fall Semester 2009. Three of the instructors who normally teach this course used the test as a pretest. Instructor 1 taught two sections of Math 2008 in Fall 2009, Instructor 2 taught one section in Spring 2010, and Instructor 3 taught two sections in Spring 2010. These five sections of the course represent 198 students.

\section{Results for Instructor 1}

Instructor 1 taught two courses in the Fall Semester 2009 with an enrollment of 41 and 35 students respectively. Of the 41 students attending Class 1 , four withdrew from the course. Of the 35 students enrolled in Class 2, two withdrew. The average score on the first attempt (pretest) for the classes was 62.7 for Class 1 and 63.9 for Class 2. Class 1 had a low score of 24 and a high score of 88, while Class 2 had a low score of 16 and a high score of 92 . The number of students obtaining a perfect score for the basic skills test on their passing attempt was 4 for Class 1 and 6 for Class 2. The median number of attempts on the test was three for both classes. The following tables indicate the number of times a student attempted the basic skills test.

\begin{tabular}{|c|c|}
\hline \multicolumn{2}{|c|}{ Instructor 1 - Class 1} \\
\hline \# of Attempts & \# of Students \\
\hline 1 & 0 \\
\hline 2 & 16 \\
\hline 3 & 17 \\
\hline 4 & 3 \\
\hline 5 & 0 \\
\hline $6+$ & 1 \\
\hline Gave Up & 0 \\
\hline Withdrew & 4 \\
\hline
\end{tabular}

\begin{tabular}{|c|c|}
\hline \multicolumn{2}{|c|}{ Instructor 1 - Class 2} \\
\hline \# of Attempts & \# of Students \\
\hline 1 & 2 \\
\hline 2 & 10 \\
\hline 3 & 11 \\
\hline 4 & 3 \\
\hline 5 & 6 \\
\hline $6+$ & 1 \\
\hline Gave Up & 0 \\
\hline Withdrew & 2 \\
\hline
\end{tabular}

\section{Results for Instructor 2}

Instructor 2 taught one course in the Spring Semester 2010 with an enrollment of 41 students. Of the 41 students attending this class, one withdrew from the course. The average score on the first attempt (pretest) for the class was 66.1. This class had a low score of 20 and a high score of 88 . The number of students obtaining a perfect score for the basic skills test on their passing attempt was 10 . The median number of attempts on the test was two. The following table indicates the number of times a student attempted the basic skills test.

\begin{tabular}{|c|c|}
\hline \multicolumn{2}{|c|}{ Instructor 2 - Class } \\
\hline \# of Attempts & \# of Students \\
\hline 1 & 0 \\
\hline 2 & 21 \\
\hline 3 & 11 \\
\hline 4 & 7 \\
\hline 5 & 1 \\
\hline $6+$ & 0 \\
\hline Gave Up & 0 \\
\hline Withdrew & 1 \\
\hline
\end{tabular}




\section{$\underline{\text { Results for Instructor } 3}$}

Instructor 3 taught two courses in the Spring Semester 2010 with an enrollment of 41 and 40 students respectively. Of the 41 students attending Class 1 , three withdrew from the course. Of the 40 students enrolled in Class 2, two withdrew. The average score on the first attempt (pretest) for the classes was 66.0 for Class 1 and 67.1 for Class 2. Class 1 had a low score of 32 and a high score of 100, while Class 2 had a low score of 24 and a high score of 96 . The number of students obtaining a perfect score for the basic skills test on their passing attempt test was 5 for Class 1 and 7 for Class 2. The median number of attempts on the test was three for both classes. The following tables indicate the number of times a student attempted the basic skills test.

\begin{tabular}{|c|c|}
\hline \multicolumn{2}{|c|}{ Instructor 3 - Class 1 } \\
\hline \# of Attempts & \# of Students \\
\hline 1 & 4 \\
\hline 2 & 4 \\
\hline 3 & 13 \\
\hline 4 & 11 \\
\hline 5 & 3 \\
\hline $6+$ & 1 \\
\hline Gave Up & 2 \\
\hline Withdrew & 3 \\
\hline
\end{tabular}

\begin{tabular}{|c|c|}
\hline \multicolumn{2}{|c|}{ Instructor 3 - Class 2 } \\
\hline \# of Attempts & \# of Students \\
\hline 1 & 1 \\
\hline 2 & 3 \\
\hline 3 & 16 \\
\hline 4 & 10 \\
\hline 5 & 5 \\
\hline $6+$ & 2 \\
\hline Gave Up & 1 \\
\hline Withdrew & 2 \\
\hline
\end{tabular}

Notice in the tables that a small number of students ( 2 for Class 1 and 1 for Class 2 ) "gave up" and never achieved the minimum score. These students attended the entire course, but realized they were not meeting the minimum grade of $\mathrm{C}$ for the course.

Instructor 3 analyzed the number of problems missed on the basic skills test to determine the hardest problems. For the 81 students in these classes, the table on the following page illustrates the problem number and how many times the problem was answered incorrectly on the first attempt and on the passing attempt.

The least missed problem on both the first attempt and the passing attempt was \#22. This problem required the student to convert a decimal number to a percent. The top four most missed problems on the first attempt were \#10, 7, 9, and 20 with \#10 being missed the most. The top four missed problems for the passing attempt were these same four problems in a slightly different order (\#20, 7, 10, and 9 with \#20 being missed the most). Problems \#7 and \#9 involved multiplying and dividing decimal numbers, problem \#10 required knowledge of least common multiples, and problem \#20 asked students to multiply mixed numbers. It is also interesting to note that problems \#15 and 18 share the next two locations in the list. Problem 15 asked students to convert a fraction to decimal form, while problem 18 had students subtract mixed numbers. 


\begin{tabular}{|c|c|}
\hline \multicolumn{2}{|c|}{ 1st Attempt } \\
\hline Problem \# & $\begin{array}{c}\text { \# students answering } \\
\text { incorrectly }\end{array}$ \\
\hline 10 & 64 \\
\hline 7 & 54 \\
\hline 9 & 54 \\
\hline 20 & 54 \\
\hline 15 & 53 \\
\hline 18 & 49 \\
\hline 21 & 39 \\
\hline 19 & 36 \\
\hline 1 & 31 \\
\hline 17 & 24 \\
\hline 5 & 23 \\
\hline 23 & 23 \\
\hline 6 & 21 \\
\hline 8 & 19 \\
\hline 16 & 17 \\
\hline 12 & 13 \\
\hline 25 & 13 \\
\hline 2 & 10 \\
\hline 13 & 10 \\
\hline 4 & 9 \\
\hline 14 & 7 \\
\hline 24 & 7 \\
\hline 3 & 5 \\
\hline 11 & 5 \\
\hline 22 & 3 \\
\hline
\end{tabular}

\begin{tabular}{|c|c|}
\hline \multicolumn{2}{|c|}{ Passing Attempt } \\
\hline Problem \# & $\begin{array}{c}\text { \# students answering } \\
\text { incorrectly }\end{array}$ \\
\hline 20 & 26 \\
\hline 7 & 11 \\
\hline 10 & 10 \\
\hline 9 & 9 \\
\hline 18 & 9 \\
\hline 15 & 6 \\
\hline 8 & 5 \\
\hline 2 & 3 \\
\hline 21 & 2 \\
\hline 1 & 2 \\
\hline 17 & 2 \\
\hline 25 & 2 \\
\hline 19 & 1 \\
\hline 5 & 1 \\
\hline 23 & 1 \\
\hline 16 & 1 \\
\hline 4 & 1 \\
\hline 3 & 1 \\
\hline 11 & 1 \\
\hline 6 & 0 \\
\hline 12 & 0 \\
\hline 13 & 0 \\
\hline 14 & 0 \\
\hline 24 & 0 \\
\hline 22 & 0 \\
\hline
\end{tabular}

\section{Observations/Comments from Instructor1}

As anticipated, the most commonly missed problems dealt with operations with fractions. What was surprising was the number of students who continued to miss the least common multiple question, even well into the semester. This was particularly surprising since students were able to find the least common multiple for problems in class and on an exam. The questions on which students performed the best dealt with percents. Considering this is the last topic in the course and the teaching of percents is usually rushed, this was a good result.

On the first administration of the test, the lowest score was 16. This student took the exam seven times and finally scored a 92 on the last attempt. In fact, the student was still taking the skills test on the day of the final exam.

There were 16 students still taking the test in December. Some simply put off the test until we had covered all the material, while others had trouble passing and needed almost all of the semester to be 
successful. Regardless of the reason, the fact that roughly $20 \%$ of the students were unable to score 90 or higher on a basic skills test is problematic.

\section{Observations/Comments from Instructors $2 \& 3$}

The students in the Spring classes, as well as the Fall classes, were weak at the beginning of the course. The average on the first attempt of the skills test indicates they either did not know the material or had "forgotten" much of it. We suspect that the extensive use of a calculator in recent years plays a major role in this "forgetting". Many of these students have used calculators for all computations since exiting middle school.

There were several "non-surprising" revelations in administering the basic skills test. We expected students to have problems with subtraction and multiplication of mixed numbers. The usual errors occurred, such as multiplying the whole numbers together and multiplying the fractions together. Multiplication facts appear to be a struggle for many of the students. Even when they know a correct process, the errors in multiplication cause them to answer problems incorrectly, as with subtraction problems and the decimal operations problems. Least common multiple/greatest common factor (lcm/gcf) was a misunderstood topic from the beginning. Sixty-four of the 81 students in Instructor 3's classes answered this problem incorrectly by giving the greatest common factor as the answer. Also, deciding when to use the "th" in naming the different place values was a challenge for some students initially.

Some "surprising" events occurred as well. It was amazing how many students did not realize that problem \#10 was asking for the "least common multiple" (not the greatest common factor), even after the unit on number theory. In the passing attempts of the test, 10 of 81 students continued to answer this question incorrectly by giving the greatest common factor. Place value was definitely an interesting topic. One student in Instructor 2's class assigned "five" as one of the place values. Once we developed our decimal numbers and determined the difference between terms such as tens and tenths, some students wanted to make the place values symmetric. For instance, students who were initially confused about the meaning of "tens and tenths" appeared to forget about the "ones" place completely on the next attempt of the skills test. Thus, their place value chart could be represented in the following form:

$$
\text { ... thousands hundreds tens (decimal point) tenths hundredths thousandths ... }
$$

Instructor 3's response to several students who had taken the test multiple times and committed this error was, "So where are the ONES?" The students appeared genuinely embarrassed once they realized their mistake, but why did they make this mistake? And, why did some students continue to make this error after several discussions in class and with the instructor?

We do not completely understand why some students continue to make these types of errors at the end of the course. Two possible contributing habits to these errors are that students do not read carefully and do not take their time when solving problems. Also, we have experienced a "lack of interest" among some students when attempting to further develop their conceptual understanding of numbers and operations. They enter the Math 2008 course thinking they know how to get the answers and do not need to learn any other conceptual methods. These students put forth very little effort in the course. It is as if they pass the time in the course, but never really absorb what is happening. This attitude makes it difficult to break old habits.

\section{Conclusion}

Math 2008 is an interesting course to teach. Although the concepts and skills are essential to early childhood education majors and their teaching career, many students perform poorly. It is unclear whether the poor performance resulted from a lack of basic skills knowledge, failure to remember those skills, or failure to pay careful attention to the material in the course because they assumed they already knew it.

What is clear is that after implementing a skills test in Fall 2009, instructors have found that most students started to take the material seriously, understand their weaknesses, and make an effort to learn. 
Although the mode number of attempts was three, students continued to try to pass the skills test and the course. They became aware of what they needed to work on and did so.

As instructors, our teaching can now be better focused based on the results of the initial administration of the test. We are aware of the major gaps in students' understanding and can address those gaps. Also, we recognize their strengths and can build on those. When students take the skills test, we provide feedback in the form of mathematical topics that they need to further explore. For instance, if they incorrectly answer the least common multiple problem, we direct them to additional practice on $1 \mathrm{~cm} / \mathrm{gcf}$ concepts. We do not return the skills test and do not have them practice a special type of problem. We aim to strengthen the students' understanding of the mathematical concept, not a particular problem. They should be able to answer any problem relating to that concept.

Our goal is for all students exiting Math 2008 to have basic skills for their subsequent courses and in their classrooms. While our observations are informal and anecdotal, we hope to continue studying these students. An interesting follow up will be to administer the skills test at the beginning of the next course in the students' program and examine those scores. 